\title{
Syncope of Obscure Nature
}

\author{
C. M. FISHER
}

\begin{abstract}
SUMMARY: One hundred and eleven cases of syncope or loss of consciousness are analyzed. Most are of obscure nature while some illustrate features of syncope that deserve further scrutiny. The cases are divided into six groups: 1) Resembling cardiac syncope (30 cases); 2) vasovagal syncope (22 cases); 3) features of both cardiac and vasovagal syncope (12 cases); 4) orthostatic hypotensive (29 cases); 5) akinetic seizure? (12 cases); and 6) miscellaneous (5 cases). Some groups are subdivided according to the circumstances surrounding the spells, for example, seated eating, nocturnal, associated with bowel movement, response to anticonvulsant therapy, etc. The following conclusions
\end{abstract}

RÉSUMÉ: Nous analysons 100 cas de syncope ou perte de conscience. La plupart sont de nature inconnue mais certaines permettent d'illustrer des mécanismes qui méritent une étude plus profonde. Nous avons divisé nos cas en six groups: 1) cas ressemblant aux syncopes cardiaques

$(N=30) ; 2)$ syncopes vasovagales $(N=22)$; 3) syncopes mixtes cardiaques et vasovagales $(N=12)$; 4)hypotension orthostatique $(N=29) ; 5)$ crises akinétiques possibles $(N=12)$; et 6$)$ divers $(N=5)$. Certains groupes sont sous-divisés suivant les circonstances accompagnant les crises i.e.: assis à table, nocturne, associées à la défécation, réponse aux anticonvulsivants, etc. Nous croyons pouvoir tirer les conclu- seem warranted: 1) The evidence favors the existence of a type of akinetic seizure resembling cardiac syncope; 2) loss of consciousness while seated eating (prandial syncope) may comprise a syndrome; 3) syncope related to bowel movement or abdominal pain is a striking association; 4) sporadic nocturnal syncope due to temporary hyporeactivity of baroreceptors is not sufficiently recognized; 5) alcohol ingestion may precipitate orthostatic hyporeactivity of baroreceptors is not sufficiently recognized; 5) alcohol ingestion may precipitate orthostatic hypotension. Familial syncope, syncope proneness and cold drink syncope are illustrated.

sions suivantes: 1) Il semble bien exister une sorte de crise akinétique qui ressemble à la s.ncope cardiaque; 2) il est possible que la perte de conscience lorsqu'assis à table constitue un syndrome à part, la syncope prandiale; 3) il existe une association importante entre la syncope, la défécation et la douleur abdominale; 4)le s!'ndrome de la syncope nocturne sporadique dûe à l'hyporéactivité temporaire des barorécepteurs n'est pas suffisamment reconnu; 5) l'ingestion d'alcool peut précipiter l'hypotension orthostatique. Enfin nous donnons des exemples de la syncope familiale, de la syncope aux breuvages froids et de la susceptibilité aux syncopes.
Reprint requests to: Dr. C. M. Fisher, Department of Neurology, Massachusetts General Hospital, Fruit St., Boston, M.A., 02114, U.S.A.

This study was supported in parts by NINCDS, Grant NS05152

From the Neurological Service, Massachusetts General Hospital and the Department of Neurology, Harvard Medical School, Boston.

\section{SYNCOPE OF OBSCURE NATURE}

In most cases of transient syncope or loss of consciousness a well known mechanism is readily recognized cardiac, vasovagal, orthostatic hypotensive, cerebrovascular, epileptic, hydrocephalic, etc. In some cases, however, a satisfactory interpretation is still not obtainable despite the use of modern electrocardiographic (ECG) and electroencephalographic (EEG) techniques. In this paper, the author's experience with such puzzling cases will be presented not with the prospect that the problem will be solved but rather that it will be more clearly delineated. Although these cases are not common, the condition poses a major problem for the victim and is therefore of practical importance.

The central feature in a typical episode is loss of consciousness without convulsive movement, followed by recovery within a few minutes. In some instances prodromal faintness is experienced which occasionally does not proceed to total loss of consciousness. Since the patient simply falls limp and unconscious, the clinical account does not lend itself to much elaboration and can be brief.

That others have been puzzled by similar cases is exemplified in the experience of Dhingra et. al. (1974) who studied 186 patients with chronic bifascicular block, in 30 of whom syncope (transient loss of consciousness) occurred. Using long term ECG monitoring the cause of the syncope was determined to be heart block in 6 patients, ventricular tachycardia in 5 (based on the occurrence of premature contractions), ventricular arrhythmia in 4 (none actually recorded), seizures 3 , postural hypotension 2, gastrointestinal bleeding 1 , and no cause in 9 patients. If the inference concerning the role of ventricular tachyrhythmia and arrhythmia is regarded as 
uncertain, no fewer than 18 of 30 syncopal patients with bifascicular block would be left without a satisfactory diagnosis. Furthermore, if the 3 patients with seizure had tonicclonic convulsions, the term syncope would hardly be applicable and a total of 18 of 27 patients would remain undiagnosed. In another study (Scheiman, 1973), two of 12 cases with suspected cardiac syncope continued to have spells which were unexplained despite a normally functioning pacemaker.

\section{CASE MATERIAL}

The number of cases assembled totalled 111. The majority of the patients had more than one episode. Almost always a cardiological investigation including Holter monitoring excluded, according to conventional rules, a cardiac cause of the syncope. Neurological and electroencephalographic examination excluded the commonly recognized types of epileptic seizure. Orthostatic hypotension was tested for by measuring the blood pressure with the patient lying and standing. The effect of carotid sinus pressure was ascertained. The response to ocular compression, investigated in only a few patients, was always negative. Clinical and electrocardiographic examination during an episode was not possible, but before a patient was included in the present series an account by a capable eye witness generally had to be available or the spell must have been typical in all respects, for example, loss of consciousness in the bathroom at night. Medical and neurological illnesses predisposing to syncope were ruled out. While details of the attack were usually reliable, what remained unclear was whether the mechanism was cardiac, vasovagal, orthostatic, or even akinetic seizure. "Drop" attacks and spells related to hysteria, depression and hyperventilation were set aside. Sometimes the special reason for inclusion of a case was a long term follow up.

In attempting a classification of the cases the question became "on what basis can attacks of simple loss of consciousness be categorized."? Although several different possibilities existed, arranging the cases in the following six groups according to the most likely mechanism of syncope appeared to be advantageous: 1) Cases qualifying in every respect as cardiac syncope but without demonstrable conduction abnormality; 2) vasovagal syncope; 3) cases with features of both cardiac and vasovagal syncope; 4) orthostatic hypotension; 5) akinetic seizure?; and 6) miscellaneous. Under each of these headings the cases are further subdivided according to the circumstances surrounding the spells - for example, while seated eating, in association with an alcoholic drink, on arising during the night or first thing in the morning, in association with a bowel movement or abdominal pain, a family history of fainting, the response to anticonvulsant therapy, etc.

\section{CASES RESEMBLING CARDIAC SYNCOPE}

To claim that cardiac syncope has been exluded in the cases presented here is unwarranted since nothing less than cardiac monitoring during an attack, a reliable examination of the pulse, or the recurrence of an attack after insertion of a pacemaker would provide sufficient proof. It has not been clearly determined whether cardiac syncope may occur just once or twice never to recur, nor is it known for how long sporadic cardiac syncope may occur with the ECG remaining normal between attacks. In a personal review of 100 cases of Stokes-Adams attacks from the records of the Massachusetts General Hospital, there were 5 cases in which ECG evidence corroborating the correct diagnosis did not appear for 8 years ( 2 cases), 4 years, 17 months, and 8 months, respectively. In none of the 5 cases was there hypersensitivity of the carotid sinus to external pressure. On the basis of this finding, waiting for ECG evidence of cardiac syncope may be lengthy. Nowadays a trial of an artificial cardiac pacemaker would probably be undertaken in such cases. A long term follow up during which the heart and ECG remain normal may help to exclude a cardiac mechanism, but this has not been established with certainty.

If these spells are not of cardiac origin, what other mechanism might be invoked? In 13 cases anticonvulsant medication seemed to be effective, raising the possibility that at least some of the spells represent akinetic seizures, a condition which has not been fully defined in the literature.

In 3 caes the pulse was present during an attack but assessment in the excitement surrounding an episode of loss of consciousness is not always reliable. Statements concerning the duration of unconsciousness, convulsive movements, stiffening and rigidity of the limbs, color, and sweating are not always accurate. An EEG or ECG during a spell was not possible. Electroencephalographic (EEG) recordings included response to hyperventilation and photic stimulation but other activation measures were not used. Computerized tomography (CT) was carried out in a few cases.

It is probably correct to say that the attacks to be described cannot be distinguished from Stokes-Adams attacks on clinical grounds. In the review of 100 cases of Stokes-Adams attacks referred to above, 45 had syncopal spells only, 41 had syncopal and presyncopal spells, and 14 had presyncopal spells only. Prodromal symptoms occurred in about $40 \%$ including lightheadedness, blacking out of vision, fading of hearing, vertigo, and a warm feeling spreading upwards through the body sometimes from the epigastrium suggesting the aura of a seizure. Adventitious movements of the limbs - shaking, twitching, and stiffening - occurred in $23 \%$ of the cases of syncope. Also recorded were rapid labored breathing, deviation of the eyes, cyanosis, urinary or fecal incontinence, sweating, nausea and vomiting. While in most cases the duration of loss of consciousness was less than 3 minutes, in 12 it was estimated to be from 7 minutes up to 5 hours. Clearly, the clinical manifestations of StokesAdams attacks in their variability may rescmble vasovagal spells or cerebral seizures and cannot serve as the basis for a precise diagnosis.

\section{A) Cases in which anticonvulsant therap!' Was 'ffectiv'}

There were 13 patients in this group all good candidates clinically for the 
diagnosis of cardiac syncope, but without cardiac evidence. The ECG was normal except in case 7 in which there was right bundle branch block (RBBB). Cardiac monitoring was carried out in 7 cases. In all cases anticonvulsant medication appeared to be effective, phenytoin in 10 cases, phenobarbital in 2 caes, and clonazepan in 1 case. The pulse was taken during a spell in 3 cases and it remained strong.

Case 1. A man, aged 71, had several episodes of loss of consciousness, three observed by a physician. While eating breakfast he put his head on his arm on the table and was unconscious for 20 to 30 seconds and may have shaken a little as he regained consciousness. The pulse was strong throughout and the hands were cold and slightly cyanotic. The face was pale and the lips were slightly blue. He vomited a little and later sweated. Once, while walking, he fell heavily to the floor regaining consciousness in a few seconds and said "What am I doing here?" He was not pale. In another attack he crumpled gently to the floor, became pale and broke into profuse perspiration over the head and chest. There was a chronic progressive impairment of memory. Cardiac monitoring for 1 week was normal. An EEG was normal. On phenobarbital therapy there were no further spells in 5 years.

Case 2. A woman, aged 70 , had four spells of unresponsiveness in 4 months. She slumped unconscious, very pale, and limp without convulsing or stiffening. She regained consciousness in 1 minute and was immediately well oriented. Three attacks occurred while seated, one while standing. Cardiac monitoring was normal. An EEG was normal. On phenytoin there were no further spells in 4 years.

Case 3. A woman, aged 73, had 6 spells of unexplained unconsciousness in which she fell briefly with no seizure activity. In the first she was walking, in the second she was lecturing and fell forward off the platform and in the third was rising from the dinner table. In the fourth she was cleaning up after breakfast and found herself lying on her back on the floor. The fifth occurred while standing and in the sixth while walking on the street she suddenly fell forward striking her forehead and lacerating the temple. There was no jerking, twitching, tongue biting or soiling. In one spell she was pale. After another spell she did not recall events for half an hour. And ECG and EEG were normal. On phenytoin therapy there were no further spells in 6 years.
Case 4. A 72 year old woman in 10 months fell unconscious five times for less than 1 minute without convulsive movements. She was pale and sweaty and the eyes stared widely. A cardiac cause was ruled out. An EEG was normal. A CT scan showed advanced convolutional atrophy. On phenytoin therapy there were no further spells in 4 years.

Case 5. A woman, aged 74, in 6 months had spells 4 to 6 times weekly, in which she collapsed to the floor unconscious for a second or two, immediately regaining full awareness. On three occasions she fractured a limb. Slight pallor was noted, but no convulsive activity. On anticonvulsant medication there was only one further spell in the next 3 years. The patient showed signs of early senile dementia. An EEG showed frequent high voltage slowing in the right temporal and frontal leads. ECGs were normal. A CT scan showed cortical atrophy.

Case 6. A woman, aged 80 , for 8 years had about one spell a year, in which she felt faint and slid to the floor unconscious for several minutes without convulsing. On regaining consciousness she was nauseated. On six occasions while lying in bed she felt herself "going". An EEG was normal. Cardiac monitoring for 24 hours was normal. On phenytoin therapy there were no spells in the next year.

Case 7. A woman, aged 80 , had two major and several minor attacks. One day after feeling nauseated she was found in a chair totally unresponsive, very pale and drooling. Twenty minutes later she regained consciousness and in the next hour slowly regained her memory. In another spell she felt like vomiting, ran into the room holding a basin, and lost consciousness for 1 minute. On another occasion while shopping she sat down on the floor and lost consciousness. Nausea was present in all attacks. Convulsive activity was never observed. An EEG was normal. There was no orthostatic hypotension. An ECG showed RBBB and PR $0.23 \mathrm{sec}$. Cardiac monitoring was negative. On phenytoin therapy there were no spells in the following 4 years.

Case 8. A man, aged 73, lost consciousness three times in 6 months once while eating and twice while sipping tea. In the first he lost consciousness while seated, his head fell forward on his chest, and he was out of touch. Three hours later the same thing happened when, while having a cup of tea, he suddenly vomited, became very pale, and his head fell forward again. ECG monitoring for 1 week was normal. An EEG was normal. Five months later while having morning tea he slumped and was again unconscious, pale and clammy. $\mathrm{He}$ did not realize he had lost consciousness. An EEG was again normal. The patient lived 5 more years and on phenytoin therapy had no further spells.

Case 9. A woman, aged 62, had two spells 3 years apart. In the first she called out "I'm going" and was caught by her nephew before she struck the floor. She was incontinent of bladder and bowel. In the second she complained of pain in the right foot, was helped to the kitchen and blacked out for a few seconds, again with double incontinence and no trace of convulsive activity. An EEG was normal. There was no orthostatic hypotension. Phenytoin therapy was effective in the next 4 years.

Case 10. A man, aged 68, had two attacks in 2 hours and 2 months later two attacks in 20 minutes. In the first one he awakened at midnight and said "I'm going, I'm going, the pain is terrific" and lost consciousness for 3 minutes. He was chalk white, soaking wet in a cold sweat and gasping for breath. There was no jerking, twitching or frothing. He talked sensibly almost immediately. He went back to sleep and 2 hours later a similar spell occurred, again first with a cry of pain. He was back to normal in 3 minutes. He did not realize he had lost consciousness. There was no deviation of the eyes or head and no tasting movements. Two months later he lay down, looked pale and said "Oh, it's the trouble" and lost consciousness. There was no jerking. Twenty minutes later while being examined by his family physician he had a spell during which the pulse was maintained. $\mathrm{He}$ was ashen and sweaty following which he regained consciousness and talked intelligently. There was a headache with each spell but in none was there incontinence or tongue-biting. Headaches which had been present on and off for 2 years were getting worse. One year before while coming out of a restaurant he had fallen and fractured his ankle without recalling what had happened. An EEG, ECG and CSF examination were normal. The patient was begun on phenytoin therapy and there were no further spells in the next 9 years. He had become demented.

Case 11. A woman, aged 79, lost consciousness twice in seven weeks. Each time she was seated and the second episode was witnessed. She first swayed and did not respond. The pulse was strong but slow. She was pale and sweaty, the eyes were open. Saliva drooled from the mouth. Breathing was quiet. She was held upright and did not regain consciousness for 10 to 
15 minutes. Suddenly she yawned and within 15 seconds blinked, became fully aware and said "I'm fine". There was no convulsion, stiffening, incontinence or tongue biting. An EEG was normal. Aortic stenosis of moderate degree was regarded as asymptomatic. Cardiac monitoring showed no conduction abnormalities.

Case 12. A woman, aged 87 , in 10 years had had seven spells in which she stared or fell and was incontinent of urine and once of feces. She had a "funny" color and regained consciousness in 3 or 4 minutes. Memory was becoming progressively impaired. An EEG showed diffuse 6-7 Herz activity. An ECG showed normal conduction times. The sinuses were not sensitive to pressure. On phenobarbital therapy there were no further spells in 2 years.

Case 13. A woman, aged 70, while upstairs fell limp as if dead and was unconscious for more than 20 minutes without convulsive movements. Five months later, while seated, she lost consciousness and was lifted bodily to a couch. She was pale and limp without jerking. She began to regain consciousness in 20 minutes and was confused. The next day she was lucid. In another spell, while seated, she slumped over a table, opened her eyes in a few minutes and did not recognize her family physician. An ECG and EEG were normal. The patient had a history of depression treated with 100 applications of electroshock. On phenytoin therapy there were no further spells.

Summary of cases. Ten of the patients were women and 3 were men, a preponderance of women that may be of interest. All were over 70 years of age except for two who were in their 60 's. Twelve patients had 2 to 8 spells and one had more than 100 . The duration of unconsciousness was less than 1 minute in 6 patients, 1 to 3 minutes in 4 and up to 20 minutes in 3. In 2 patients there was an aftermath of confusion that lasted up to an hour. Pallor was reported in 10 patients, sweating in 5 and nausea and/or vomiting in 4 . Incontinence of bowel and bladder occured in 2 . In 4 patients memory was failing but in the others intellectual function was well preserved. An EEG was normal in 11 patients and in the other two showed frequent high voltage slowing on the right side and diffuse 6-7 Herz activity respectively. The length of follow-up was 2 to 9 years in 10 of the cases.
Comment: There probably is no way short of ECG or EEG recordings during a spell that the true nature of the cases can be identified on the basis of present knowledge. Could this be a fortuitous collection of patients in whom the diagnosis of Stokes-Adams attacks is limited by current appreciation of the vagaries of cardiac syncope? Is the absence of a cardiac abnormality in the long term followup periods of significance? Is there an unrecognized trigger that sporadically evokes cardiac syncope via the vagus nerve as in carotid sinus sensitivity or with visceral pain? These questions are unanswered. The female-male ratio in the present group was 3.3:1 whereas in Stokes-Adams attacks it was 0.5:1. In none of the cases was a trial insertion of a cardiac packmaker made.

Could the cases be ordinary seizures in which inaccurate observation failed to note minor convulsive activity? An effort was made to avoid such an error. The favorable effect of anticonvulsant medication supports the seizure theory, but on the other hand, the EEG was normal in 11 of the 13 cases. It is most unlikely that the antiarrhythmic property of phenytoin could have halted Stokes-Adams attacks. Another possibility is that phenytoin was effective in preventing reflex cardiac syncope similar to its occasional remedial action in glossopharyngeal neuralgia. In the entire series, it was in the cases that looked like cardiac syncope, but in whom the cardiac findings were normal that anticonvulsants were effective. From this experience it might be suggested that cases of syncope not clearly vasovagal or orthostatic hypotensive be considered for anticonvulsant therapy, if the cardiac findings are normal.

The literature contains very few references to akinetic seizures and most deal with special features rather than addressing the main subject. Gastaut et. al. (1974) in summarizing their experience concluded that, apart from the brief lapses of petit mal epilepsy, atonic (or akinetic) spells had two distinct etiologies, the first occurring in very young children and triggered by hyperthermia or transient metabolic disturbances and the second occurring in adults with either obvious or suspected focal organic brain lesions, most often in the frontal lobe, and usually accompanied by another form of seizure commonly focal with secondary generalization. The present series of cases do not find a place in that classification and would represent a novel type of late-life akinetic seizure.

The possibility must be entertained also that the spells are of an heretofore unrecognized nature, neither syncope nor seizure, but further speculation is unwarranted.

\section{B) Syncope while eating}

Case 1. A man, aged 63, in 3 months lost consciousness twice and felt faint once, each time while eating. In the first, at supper, he regained consciousness having vomited down his front. The attack lasted 1 minute and he sweated heavily. In the second spell 11 days later he got up after eating, began to fall and regained consciousness about 1 minute later sitting in a chair sweating heavily. In the third, while eating lunch, he felt faint and was observed to be sweating sopping wet across the shoulders. There were no convulsive movements and he was not confused. There was no tendency to recur. An EEG was normal. An ECG showed left axis deviation (LAD) and minor ST segment and $T$ wave abnormalities. ECG monitoring revealed no arrhythmia. Four months later the patient had an acute anterior myocardial infarction uncomplicated by arrhythmia.

Case 2. A woman, aged 82 , while sitting eating dinner felt faint for several seconds and then lost consciousness for 10 minutes. An ECG showed a rate of 60 per minute and PR 0.20. A pacemaker was inserted despite which she had two further similar spells while eating, in the next two years. There were no convulsive movements.

Case 3. A man, aged 55, in the middle of his noon meal slumped unconscious, pale and sweating. He regained consciousness when placed on the floor. An ECG was normal. There was no recurrence in 11 years.

Case 4. A man, aged 69, while seated at breakfast, toppled onto the floor without warning and was unconscious briefly, scaring the family "half to death." An ECG was normal. This was the only episode. There was no recurrence in the next 20 years. ECGs remained normal.

Case 5. A man, aged 40, while drinking coffee, seated at 10:30 a.m. fell from his 
chair to the floor. He was unconscious briefly and there was no convulsion. An ECG in the Emergency Department showed no abnormality. This was the only episode and there was no recurrence in the next 25 years. Annual ECGs remained normal.

Case 6. A man had two spells, one at the age of 62 and one at the age of 65 , both while eating. He became pale and slumped unconscious for about 1 minute. Myocardial infarction occurred at the age of 66 but there were no syncopal attacks in 8 years.

Case 7. A man, aged 71, while eating toppled onto the floor unconscious. It was the only spell in 6 years. An ECG was normal.

Case 8. A man, aged 61 , at dinner in the evening, felt faint and the next thing he knew people were hovering over him. He was sweating. The waiter said "You looked like death." He had had a myocardial infarction 20 years before but there was no ECG evidence of a conduction defect.

Case 9. A woman, aged 87 , after lunch stood in front of the fireplace and came to her senses having fallen heavily and struck her head. The spell was witnessed and there was no convulsion. No cause was found and there was no recurrence. There was no postural hypotension.

Case 10. A man, aged 57, while sitting eating toppled off onto the floor and regained consciousness in 40 seconds. The scalp was lacerated. There were no convulsive movements. An awake EEG and cardiac monitoring for 2 days were normal. There was no recurrence in the next year.

Case 11. A man, aged 85, slumped and lost consciousness at the dinner table.

Summary: There were 11 cases in which syncope occurred in relation to eating, in 10 instances while the patient was seated. Again cardiac syncope may well have been the mechanism but ECGs failed to corroborate that diagnosis. Nine of the patients were men and two were women. The ages ranged from 40 to 87 with 8 more than 60 and 3 less than 60 years. Seven patients had only one spell, two had 2 and two had 3 spells. The duration of the spells was brief. ECGs in all cases were free of conduction abnormalities. An EEG made in two patients was normal. The follow-up period in 7 cases ranged from 1 to 25 years. Only two patients had a myocardial infarction subsequently, 4 months and 2 years later respectively. In one case, a functioning artificial pacemaker failed to prevent attacks. Stokes-Adams attacks occurring during eating are relatively uncommon and in a series of 100 cases there were only three - one patient who had one attack showed congenital RBBB, one patient who had three attacks showed 3:1 heart block and one patient whose attacks typically occurred after eating showed a normal ECG but hypersensitivity of the carotid sinus reflex to pressure was present.

Comment: In this group also the mechanism of the episodes remains obscure. It would be unusual for there to be freedom of spells for up to 25 years after 1 or 2 episodes of cardiac syncope, at least as the process is understood at the present time. Sporadic reflex cardiac syncope remains a possibility and this is remarked upon below under Heading No. 3.

\section{C) Reflex Cardiac Syncope}

The only case placed in this group concerned a patient whose spells were related to swallowing a cold beverage.

Case 1. A man, aged 61, had about 15 attacks of unconsciousness each year for approximately 32 years. The spells came suddenly with a brief prodrome of sweating, faintness and feeling hot. He had learned to lie down quickly to avoid injury although on one occasion he had sustained a scalp laceration. He had been told he was pale. There was no convulsive activity. The usual duration of a spell was a few seconds and always less than a minute. Recovery was prompt and the patient continued with his daily activities. He had casually observed that the attacks might be related to drinking cold orange juice or water. An ECG was normal. The blood pressure was 130/80 without postural fall. An EEG was normal.

While recording the ECG under resting conditions carotid simus pressure produced a normal reaction. When given tap water at about $60^{\circ}$ Fahrenheit to drink there was no change. On drinking $4 \mathrm{oz}$. of ice water the pulse slowed from 78 per minute to 30 per minute and during the period of recovery carotid sinus pressure produced cardiac arrest for 7 seconds. When ice water was held in the mouth for one minute before swallowing there was no untoward effect. The spells ceased when the patient avoided cold drinks.

Comment: Only one reference to a possibly similar phenomenon was found in the literature, Simpson (1949) describing a nervous, young, pregnant woman who drank a glass of cold water and fell to the floor dead. Necropsy revealed nothing to explain the event.

\section{D) Miscellaneous cases}

Case 1 . A vigorous woman, aged 90 , in the previous 3 years had four spells in which she lost consciousness for about 30 seconds. Near the end of the spell there was a gurgling sound in the throat and she vomited a little. On one occasion when sitting across a table from a relative she stared, failed to answer and sat quietly for about 30 seconds with eyes open and straight ahead. There was no twitching, jerking or stiffening. In one spell the patient was incontinent of urine and in another of feces. An ECG was normal. The carotid sinuses were not sensitive.

Case 2. An 84 year old man with Parkinsonism fell unconscious for about 3 minutes, five times in a period of 5 years. In the spell he breathed heavily but was otherwise akinetic although the jaw was closed. Afterwards he was pale, sweating, confused, disabled for a few hours and did not recall falling. There was no incontinence or tongue-biting. An ECG and EEG was normal.

Case 3. A senile woman, aged 90 , in 4 months had several attacks in which she fell unconscious for 2 to 3 minutes without jerking, twitching or incontinence. A nurse was in attendance at all times. Orthostatic hypotension was excluded. An ECG was normal.

Case 4. A man, aged 51, while bending over in his store developed numbness of both arms and lost consciousness for about 4 minutes. Initially pale, he was restored in 5 minutes. In a second attack he bent over to get a loaf of bread and slumped to the floor, again pale. An ECG and EEG were normal. The resting pulse was 54 .

Case 5. A woman, age 56, while standing slumped to the floor and was unconscious briefly. There was no convulsive activity, but she vomited. There was no recurrence in the next 12 years.

Comment. The five patients in this group illustrate the difficulty in classification. If a category of akinetic seizures existed, the first three cases would be candidates. Case 4 remained 
obscure and in Case 5 syncope might have been vasovagal.

\section{CASES OF VASOVAGAL SYNCOPE}

Twenty-two patients seemed to fit best under this heading, although in several instances the decision was open to question. In addition to pallor, sweating and fainting the single feature that strongly favored the interpretation of vasovagal syncope was the recurrence of faintness on standing up again after having recovered while lying down. This is an uncommon event in Stokes-Adams cases which is associated with bradycardia and invariably an abnormal ECG. The onset of syncope was generally more gradual than in cardiac syncope.

\section{A) Associated with Defecation or Abdominal Pain}

There were 11 patients in this group. In Cases 1, 2 and 3 the relation of syncope to a bowel movement was complex and unusual, almost comprising a special syndrome. In Cases 4 , 5 and 6 diarrhea was a factor. Case 11 was included as an unusual problem. Whereas, fainting during micturition is well recognized, a relationship with movement of the bowels is not. In attributing significance to defecation or abdominal pain it must be borne in mind that vasovagal syncope in itself may be associated with a feeling of having to defecate but in the present cases the urge appeared to precede faintness. Straining so as to produce the Valsalva effect was not a factor.

Case 1. A woman, aged 69, since childhood had attacks once or twice a year in which syncope occurred in association with crampy abdominal pain and an urge to move the bowels. Attacks usually occurred in the morning. She was unconscious for about 1 minute and was immediately oriented on recovering. "I feel the blood rushing to my head, I must run to lie down, but I feel a terrific pain in my stomach, my bowels have to move so I go the bathroom and blackout." On first going to the toilet she might have a small bowel movement and then be obliged to lie down lest she faint. On going back to the toilet to complete the bowel movement she would lose consciousness a second time. She slumped to the floor, pale, covered with sweat, without jerking, twitching or incontinence of urine. She was "the picture of death", according to her husband who was employed in a funeral establishment. If she arose too quickly, fainting recurred. Attacks occurred while standing or seated, more often when standing. Her usual bowel movements were normal without crampy pain and faintness each time was associated with a distinctive specific crampy pain. An EEG and ECG were normal.

Case 2. A man, aged 68, about once a year for 11 years had fainting spells in which he awakened with a desire to move the bowels, rushed to the bathroom, had a violent bowel movement and lost consciousness. The pupils were large, the pulse was slow and faint and the patient was very pale, cold and bathed in sweat. Sometimes he had one bowel movement that was mild, followed 15 minutes later by a second one which caused him to sweat, feel nauseated and collapse. In at least 6 attacks he had urgent, explosive diarrhea, vomited, lost consciousness at the toilet and fell to the floor where his wife found him lying in vomitus. All attacks except two occurred at night. There was no convulsive activity. An EEG was normal. Between attacks the sensation to move the bowels was normal.

Case 3. A woman, aged 56, in 2 months had 3 fainting spells preceded by a peculiar indescribable sensation in the epigastrium and a feeling of faintness in the head. The first spell came while she was seated and on lying down she immediately had an urge to move her bowels. The second spell came in the middle of the night again with epigastric and cranial distress. She became pale, sweated, ran to the bathroom and within a few minutes of the onset had the urge to move her bowels. Recovery took 45 minutes. The third attack came on finishing dinner when she went out to get fresh air and lost consciousness for a few seconds again with the urge to move her bowels. In the last spell she was ghastly white and incontinent of urine. There was no postural hypotension. An EEG and ECG were normal. There was no recurrence in 7 years.

Case 4. A man, aged 47, while a passenger on a commercial air liner, got up to rush to the bathroom and after 15 steps lost consciousness and came to his senses lying on his back in the aisle. He got up, went to his seat and was dazed but at the end of the flight was able to drive his car. In the past he fainted twice during episodes of diarrhea falling off the toilet, first at the age of 17 and again at 24 Periodically on squatting to pick up something he became light-headed and had to hold on to steady himself for 2 or 3 seconds. An EEG and ECG were normal. On rising from the squatting position the blood pressure was lower than $80 \mathrm{~mm} . \mathrm{Hg}$ systolic for about 12 seconds and then rose to $100 / 85 \mathrm{~mm}$. $\mathrm{Hg}$.

Case 5. A man, aged 28, had diarrhea, nausea and vomiting on a commercial air plane flight. He felt faint, got to his feet and fell unconscious to the floor with clenched teeth and head extended stiffly for a second or two. He was unconscious for 7 seconds. He lay on the floor for 5 minutes then returned to his seat when the same thing happened again and he was unconscious for a few seconds. He sweated heavily. There was no information about pallor. At the age of 23 during a bout of diarrhea the patient had lost consciousness but the details were unknown. The patient's resting pulse was between 40 and 50 beats per minute. An EEG was normal.

Case 6. A man, aged 58, had several fainting spells associated with diarrhea or cramping abdominal pain. Eight years before admission during a bout of gastroenteritis he had 4 or 5 watery bowel movements, vomited once or twice and while seated on the toilet fell unconscious. Seven years before he got out of bed at night and while putting on his slippers fell forward on the floor, unconscious, again with lower abdominal discomfort. While in the hospital he got up to walk across the room and fainted. Two years before during an upper respiratory infection he developed crampy abdominal pain after moving his bowels, began to feel faint and had to sit down on the floor. He vomited and was confused, faint and unable to rise. Three months before admission he had an episode in the kitchen when he deliberately sat down on the floor lest he fall. In the past he had had an episode of micturition syncope. There was no postural hypotension. An EEG and ECG were normal.

Case 7. A woman, aged 70, while visiting in the hospital had severe pain in her abdomen, felt faint and lost consciousness in the bathroom. She thought there had been a violent diarrheic bowel movement. Two months before in the early morning after getting out of the bathtub she lost consciousness for about 5 minutes. There was no postural hypotension. An ECG was normal except for LAD. An EEG showed occasional bilateral slow wave activity. Carotid sinus sensitivity was normal. There were no further spells in the next 10 years.

Case 8. A man, aged 70, after eating fish developed swelling of the lips and tongue 
and generalized itching. He went home, had a bowel movement and was found 30 seconds later unresponsive, seated on the toilet ashen and pulseless. He remained unconscious for 20 minutes until placed prone when he recovered. There was no twitching. An ECG was normal. There was no postural hypotension.

Case 9. A man, aged 67, had dizzy spells for 1 month. On the day of admission because of nausea and vomiting he went to the bathroom where he was soon found sitting on the toilet, unresponsive, pale, sweating and pulseless, slumped against the wall. He was kept in a sitting position and 20 minutes later examination disclosed a left homonymous hemianopia, slight weakness of the left hand and arm and severe weakness of the left leg. Four hours later he was almost back to normal. An ECG was normal. Angiography showed complete occlusion of the right internal carotid artery. Apparently fainting in the bathroom had resulted in ischemia in the territory of the occluded right carotid artery.

Case 10. A man, aged 65, had fainted easily all of his life - the sight of blood, cutting a finger, etc. Once while having a bowel movement he developed severe abdominal pain, felt faint, managed to get to a nearby chair and was found unarousable, pale, sweating and limp. There was no seizure. Breathing was about 32 per minute. On being placed on the floor he soon regained consciousness.

Case 11. A man, aged 58, for 1 year had vomiting spells which occurred irregularly about once a month. Each attack began with a dull pain, not crampy, starting at the sides of the abdomen and moving towards the center. In 5 or 10 minutes he began to sweat heavily, became pale and vomited several times. The pain lasted an hour during which period the sweating continued. The spells usually occurred 1 hour after breakfast. All laboratory studies were negative. The spells were still occurring 3 years later. Although the patient did not lose consciousness, the case exemplifies attacks of sweating and pallor with episodic abdominal pain of undetermined nature.

Comment. Eight of the patients were men and three were women. Their ages ranged from 28 to 70 years. There was only one episode in 5 cases, while the number ranged from 2 to many in the others. ECGs and EEGs were normal in 10 cases. Four patient (Cases 4, 6, 7 and 10) had fainting spells on other occasions. In none of the patients was postural hypotension present on the usual tests. One patient had transient hypotension on rising from a squatting position.

\section{B) Associated with eating}

In these three cases the symptoms were consistent with a vasovagal mechanism although in Case 3 an abnormal EEG may be significant.

Case 1. A man, aged 46, had two episodes of unconsciousness 2 weeks apart. In the first while sitting in a restaurant he got a cramp in a calf of his leg, went to the bathroom and lost consciousness. According to witnesses, on getting up he became as white as a sheet, sweated and fainted again. Two weeks later sitting at the table having an alcoholic drink he said "I think l'll pass out" and lost consciousness for 10 minutes. Each time he sat up he would again feel faint. There was no seizure. There was no history of fainting as a child. An ECG was normal. There was no postural hypotension. There was no recurrence in 10 years.

Case 2. A man, aged 28, in the middle of the main course of a late evening dinner suddenly became cold, faint, pale, sweaty and unable to breathe easily. He walked 50 feet to his car and while standing fell to the sidewalk unconscious for about a minute. His wife was with him and affirmed that there were no convulsive movements. On regaining consciousness he vomited once and remained pale and weak. The next day he was well. One and a half years later, again during a late evening dinner, he had the same prodromal symptoms, went to the bathroom and lost consciousness, coming to his senses, lying on the floor face down in a pool of blood. On trying to get up he again felt faint and had to sit with his head between his knees. When found he was pale and sweaty. Neither spell was preceded by nausea or diarrhea. He had 60 $\mathrm{ml}$ of alcohol on each occasion, an unusually small amount for him. Neurological examination was normal. An EEG, ECG and CT scan were normal. There was no postural hypotension and carotid sinus sensitivity to pressure was normal.

Case 3. A man, aged 76, in 2 years had about 10 spells of faintness without loss of consciousness. All except one occurred while seated eating at noontime, twice in the same restaurant. One occurred while standing in line on a very warm summer day. The spells began with a faint feeling, pallor and sweating that wet his hair. $\mathrm{He}$ said "l'm getting sick" and walked to where he could lie down saying "I'll be okay." His knees felt weak. In about 20 minutes he recovered and there was no recurrence of fainting if he arose too soon. Usually he had an urgent bowel movement immediately afterwards. After one spell he was confused for half an hour. There were no convulsive phenomena. The patient had angina pectoris but the spells were not related. The patient was subject to fainting as a boy. The carotid sinuses were not hypersensitive to pressure. There was no postural hypotension. An EEG showed a marked abnormality in the form of intermittent bursts of bilaterally synchronous high voltage slow waves, sometimes sharp and triphasic in character, more prominent posteriorly. The blood cholesterol level was $106 \mathrm{mg} . \%$. Phenytoin was probably effective.

These cases will be discussed in Group 3 .

\section{C) Syncope Proneness}

These 3 patients are included simply to document examples of a life-long tendency to syncope. In many spells, the responsible triggering circumstances remain as unclear as in most of the cases of the entire series. Fainting while seated, eating, occurred in all three.

Case 1. A man, aged 80 , had fainted at intervals throughout his life. Bradycardia of 40 to 45 beats per minute and low blood pressure were present since scarlet fever as a youth. In high school he fell off his seat on to the floor. At college he fainted when a friend was injured. In the Army he fainted with typhoid vaccination. Once sitting in a restaurant he fell from his chair to the floor and was unconscious for a few minutes. Another time while seated in a theater he complained of nausea and suddenly toppled on to the floor. He fainted on one occasion while at work, according to a colleague. At the age of 45 he fainted while eating breakfast. He got up and went for fresh air, came back and again fell unconscious off his chair. At the age of 65 , while seated at a meeting, he felt faint and weak, put his head down on the table and lost consciousness for 3 or 4 minutes. Fifteen minutes later the attack was repeated and he was unconscious for 1 hour, very pale and was wringing wet. Slight dysphasia and a right hemiparesis were present for 1 hour afterwards. In the years following this major faint the patient had about 4 spells each year in which he would feel light-headed and have to lie on the floor lest he faint. For the last 30 years ECGs showed sinus bradycardia with atrial extrasystoles but there was no 
change over the years. On standing up from lying the heart rate approximately doubled. The blood pressure was $140 / 80$ $\mathrm{mm}$. $\mathrm{Hg}$ lying and $80 / 60 \mathrm{~mm}$. $\mathrm{Hg}$ on standing with prompt recovery to $110 / 80$ $\mathrm{mm}$. Hg. The pulse varied from 36 to 46 per minute. There was never any seizure activity, an EEG was normal, and phenytoin therapy was ineffective. Two sons had life-long bradycardia without syncope.

Case 2. A man, aged 54, described fainting spells in himself, his wife and their 3 children. The patient had fainted while reading about appendicitis, while waiting to donate blood, during intravenous pyelography and on two occasions while having blood drawn. Three years before admission he lost consciousness after a full meal in a commercial airplane over Chicago. He did not recall any preceding anxiety. Six months before, after a snack, while driving his car and sipping a refreshment, he lost consciousness at the wheel without an accident. He had other fainting spells in which he felt he was "leaving this world."

His wife fainted with each pregnancy. She also fainted three times while out dining and if she got up too soon she would lose consciousness again. One of the patient's sons fainted while at the dinner table and on another occasion on standing up after eating he fell and broke a tooth. Once after finishing his dinner he said "I'm getting a pain in the stomach" and lost consciousness for 30 to 40 seconds. Another son fainted at the age of 16 falling and fracturing his jaw, and a daughter fainted when receiving an injection. All tests in the patient were normal including an ECG and EEG. There was no postural hypotension.

Case 3. A woman, aged 61, with ease of fainting in her early years, for three years had attacks from none to three a week. In some she fell down, very pale and on regaining consciousness was immediately clear. One occurred sitting at the table after lunch, another in church. There were many episodes of faintness relieved by lying down. Examination showed severe bilateral carotid stenosis but endarterectomy failed to relieve the symptoms. There was no postural hypotension. ECG was normal.

\section{D) Miscellaneous}

In these cases no pattern of events was recognizable but the mechanism appeared to be vasovagal.

Case 1. A man, aged 68, had four episodes of fainting or faintness. In the first episode two years before he was seated at the luncheon table when he vomited precipitously on to the table and became pale. He then lost consciousness and was held upright in his chair for 30 minutes before being placed horizontal. He recovered in about 1 hour and in 24 hours felt well. The pulse was normal after lying down. One and a half years before while seated he felt faint, walked 50 yards to a restaurant, became very pale and had to be supported. Five days later, while seated, he experienced buzzing in the ears and felt faint again. Six months before on getting up in the night to go to the bathroom he felt faint. Three weeks later one evening on bending over he felt faint, and lost consciousness for 1 or 2 minutes. The fingers and toes were cold. Investigations during the 2 year period showed no abnormality of the ECG or EEG. There was no postural hypotension. There was no undue carotid sinus sensitivity. The first two major spells were unlike StokesAdams attacks and suggested either vasovagal syncope or an unusual seizure.

Case 2. A man, aged 67, at 5:00 p.m. while seated became nauseated and faint, sweated heavily, lost consciousness and lay on the floor. After $1 \frac{1}{2}$ hours he was brought to the Emergency Department where his temperature was $93^{\circ}$ Fahrenheit. He still felt faint. His temperature returned to normal.

Case 3. A woman, aged 48, while working in a school cafeteria said "I feel funny", fainted and the radial pulse could not be obtained. There were no further spells in the next 20 years.

Case 4. A man, aged 44, while walking down the street on a hot day suddenly broke into a sweat, felt light-headed and thought he would faint. There was no recurrence in 18 years.

Case 5. A male student, aged 20, had five spells each about 3 weeks apart. There was a sudden loss or blurring of vision in the outer corner of the left eye, accompanied by a sharp pain in the right mastoid region causing him to feel weak and faint requiring support. After 3 minutes vision returned to normal. Examination was normal. A diagnosis of migrainous aura with faintness was made.

Comment: In Cases 1 and 2 fainting occurred while the patient was seated. Cases 3 and 4 represent single sporadic fainting episodes with no recurrence in many years. Case 5 may exemplify another circumstance in which fainting occurs, namely, migraine. Loss of consciousness with migraine is described in the literature but a definite case has not been examined personally except when a relation to epilepsy existed.

\section{CASES COMBINING FEATURES OF BOTH CARDIAC AND VASOVAGAL SYNCOPE}

In these 13 cases the episodes in some ways resemble syncope of cardiac origin and in others syncope that is vasovagal in origin. The combined category provides a truer picture than accommodating the cases under headings 1 or 2 .

\section{A) Syncope while eating}

Case 1. A man, aged 64, had 5 episodes of complete loss of consciousness and 2 partial. The first one, 3 years before admission occurred while seated just after starting to eat. He had had a shrimp cocktail, felt sick, lost consciousness, fell forward over the table, and vomited. On regaining consciousness he was pale, sweaty and shivering with the cold. The second occurred while he was eating supper and without warning he lost consciousness and vomited over the table. On recovery he went back and finished his meal. The third occurred at midnight Mass when he was fasting. He became sweaty, was as pale as a ghost and put his head between his knees for 5 minutes. He had been faint at Mass in the past. In the fourth spell which occurred while eating supper he felt sick, got up to go to the bathroom, walked into a brick wall and fell unconscious. In the fifth, just after finishing eating in a restaurant he felt nauseated, went to the bathroom and on the way fell, striking his head. He was incontinent of bladder and bowel. Again he was pale. He was unconscious for 5 to 10 minutes and regained consciousness lying on the floor. There were two other smaller spells, one 2 months 'before when while sitting after eating he felt he needed to move his bowels, went to the bathroom, felt sick, put his head down and sniffed ammonia. At least three spells were partially aborted by putting his head between his legs. He thought the first feeling each time was an urge to move the bowels followed by nausea. There was no convulsive activity. He was always lucid immediately afterwards. There was no postural hypotension. The pulse was 50 to 60 beats per minute. An ECG showed left ventricular hypertrophy. A cardiologist found no evidence of cardiac syncope. Carotid sinus sensi- 
tivity to pressure was normal. An EEG was normal.

Case 2. A man had two brief spells of unconsciousness, one at age 54 and one at 69 , both while sitting at the luncheon table. The patient became pale, lost consciousness and fell forward over the table. There was no seizure, incontinence or tonguebiting. Ther was no tendency to recur in the first spell but in the second he was faint as long as he was kept sitting and improved when placed flat. An ECG and EEG were normal.

Case 3. A man, aged 72, while seated in a crowded room listening to an after-dinner speaker just following eating gave two rather loud sighs (or yawns). His color was poor, his head fell forward on his chest, respiration was not visible and he did not respond when nudged. A physician found the radial pulse absent. He was laid on the floor and the pulse, which was being taken continuously, returned immediately. Respiration began again, color improved and shortly consciousness was restored. $\mathrm{He}$ was not confused. There was no convulsion or incontinence. Sweating was not noted. Cardiac monitoring for 24 hours showed no abnormality. An EEG showed bilateral paroxysmal slowing, sharp activity, and positive spikes more on the right side. A CT scan was normal. The carotid sinuses were not sensitive. Examination 3 months later showed a postural fall of blood pressure from 160 to $120 \mathrm{~mm}$. $\mathrm{Hg}$ systolic. The patient said that sometimes he felt generally weak after climbing stairs, and on one occasion was close to fainting. There was no recurrence in 1 year.

Case 4. A man had three similar spells, 2 at the age of 66 and one at the age of 73 . Without warning he lost consciousness for about 15 seconds and was immediately lucid. He lay pale and limp with closed eyes, without sweating, seizure activity or incontinence. Respiration may have ceased. Two spells occurred when the patient was seated eating and one occurred while standing. After one spell there was a recurrence within 5 minutes when the patient sat up again, suggesting vasovagal fainting as the mechanism. An EEG and ECG were normal. Carotid sinus sensitivity to pressure was normal.

Case 5. A man, aged 60, after eating a big meal toppled off his chair and was unconscious for about 30 seconds. Initially he was pale and perspiring. There were no convulsive movements. On getting up he again became pale. An ECG was normal. Carotid sinus sensitivity to pressure was normal.
Case 6. A man, aged 73, while standing shortly after lunch, fell to the floor and was very pale. He started to get up in 10 or 15 seconds and in 2 minutes felt fine. There was no sweating and no convulsion. Two years before he had fainted on getting out of bed in the morning. He went to the kitchen and while eating again felt faint and fell forward, burning himself in a cup of coffee. He had had a myocardial infarct several years before. An ECG showed no abnormality of conduction. There was no recurrence in 7 months.

Case 7. A woman, aged 51, while sitting at the table eating became pale and faint and felt better on lying down. There was no recurrence in 24 years.

Case 8. A man in his 20s, while sitting eating, felt faint and tried to get up but fell on the floor, unconscious, limp and pale without convulsive activity. Detailed investigation failed to show the cause.

Case 9. A man, aged 30, ate too much dinner, felt uncomfortable, went to the bathroom and apparently fell to the floor unconscious. He had vomited. There had been no preceding faintness. An ECG was normal.

Summary: All patients but one were male. Their ages ranged from 20 to 73 years. Six patients had only one spell, the others, 2 to 5 . All episodes were brief. Eight patients were seated when faintness began. In 4 patients the symptoms recurred on getting up too soon. Pallor occurred in all patients. Syncope occurred at any point throughout the meal. Four patients reported fainting under other circumstances than eating.

Comment: Attributing significance to the development of symptoms while the patient is eating may be unwarranted but the fact is that under headings 1,2 and 3,35 of 65 patients had episodes related to eating. A factor of selection was not operative since the circumstances under which syncope occurred were not a criterion for inclusion in the series. The association with eating has been termed "prandial syncope". (Fisher, 1967) The sudden onset of faintness while seated is unlikely to be the result of primary postural hypotension and suggests a cardiac or vasovagal mechanism. One might speculate that a reflex whose afferent arc lies in the gastrointestinal tract is responsible; nonetheless the striking intermittence of symptoms remains unexplained. Experienced radiologists report no tendency for patients to faint during barium studies of the upper gastrointestinal system. As already mentioned, there is no special predilection to the occurrence of Stokes-Adams attacks while eating. Bonduelle and Sallou (1956) described 7 cases of "digestive epilespy" characterized by abdominal pain sometimes accompanied by nausea, vomiting or bowel movement followed by loss of consciousness or convulsion. They lasted a few minutes, began and ended suddenly and were not related to meals. The present cases seemed not to fall within their description.

\section{B) Miscellaneous.}

Case 1. A man, aged 67, between the ages of 59 and 64 had several episodes of loss of consciousness. Once while sitting in a restaurant after eating he felt hot and went to the bathroom and was found there unconscious and extremely pale. There was a recurrence at the age of 60 after eating. On another occasion while going upstairs he fell unconscious, breaking two ribs, his glasses and watch. A full laboratory investigation was normal. At the age of 62 he lost consciousness in the barber's chair and recovered by the time he arrived at the hospital. At 63 while out at dinner he became pale, fell down and vomited. An ECG and EEG were normal. He was free of spells in the next 4 years.

Case 2. A man, aged 91, recalled that when about 50 years of age he had two fainting spells. The first occurred at breakfast when while seated he fell sideways and broke his glasses, coming to his senses immediately. He sweated heavily. In the second, in his office while seated he lost consciousness and on recovering was on a couch being bathed with ice water. At times he had a sensation of fainting that could be aborted by putting his head down. Forty years later he was remarkably vigorous.

Case 3. A man, aged 60, while driving along complained of acute abdominal crampy pain, slumped over and lost consciousness for 2 or 3 minutes, going past a stop light. "He was as white as a sheet." There were no convulsive movements. In the Emergency Ward 20 minutes later he was in a cold sweat and the sytolic blood pressure was $84 \mathrm{~mm}$. Hg. An ECG 
showed nonspecific ST segment and T wave changes. Cerebral angiography was normal.

Case 4. A man, aged 73, after eating dinner felt weak, began to sweat, vision was blurred and he mistook another room for the bathroom. He was placed on the floor in a sitting position, sweated heavily and remembered nothing until arriving in the hospital 10 minutes later. He had had a myocardial infarction 2 years before. An ECG showed no change. Cardiac monitoring showed no conduction disturbance. An EEG was normal. Cerebral angiography was normal.

The syncopal symptoms in these four patients were more vasovagal in nature than cardiac. Three patients lost consciousness while eating. A 40 year follow-up as in Case 2 is rare. Case 1 closely resembles the cases in la.

\section{ORTHOSTATIC HYPOTENSION}

These cases mainly concern fainting on arising during the night or first thing in the morning and are included to illustrate a well known aspect of fainting, but one concerning which a good deal of uncertainty remains in the minds of many.

Case 1. A man, aged 60, got out of bed one morning and fell unconscious across his wife's feet. After lying in bed for 15 minutes he got up again and on going to the bathroom fainted without warning and came to his senses on the floor. The period of unconsciousness each time was 4 to 5 seconds. On examination there was no postural hypotension. An ECG was normal.

Case 2. A man, aged 62, had two episodes of loss of consciousness. In the first on getting out of bed during the night he fell on the floor with a crash. He did not remember getting out of bed. There was no post-syncopal confusion. A few days later while driving along the highway his car veered off the road and a tire blew out. The patient had never fallen asleep while driving. An ECG showed LAD and LBBB. The rate was 55 per minute. An EEG showed scattered slowing in the theta range. There were no further spells in the next 4 years.

Case 3. A woman, aged 72, got up at 3:00 a.m. to go to the bathroom and on the way back to bed fainted and regained con- sciousness sitting on the floor. Five minutes later having walked back to bed, she fainted again, while sitting on the side of the bed. After resting she went to the bathroom and fainted again fracturing ribs in the fall. There was no history of fainting in the past. On examination there was no postural hypotension.

Case 4. A man, aged 65, had three episodes of syncope two while standing urinating after getting out of bed in the middle of the night. On the third occasion the patient after cutting himself felt faint but did not lose consciousness until arriving in the hospital. The patient also had numerous spells of faintness almost all in the first moments after getting out of bed in the morning. If he lay down again he felt well. There was no postural hypotension. An ECG and EEG were normal.

Case 5. A woman, aged 70, after sitting on the side of her bed got up quickly and fell to the floor. She regained consciousness immediately but did not recall the fall. Examination showed no cause. There was no recurrence in 6 years.

Case 6. A man, aged 58, after having episodic labyrinthine dizziness for about 3 weeks wakened at 2:30 a.m. and briskly got up to put down a window. He turned to go to the bathroom and came to his senses lying on the floor. There was no postural hypotension.

Case 7. A woman, aged 71, while coming out of the bathroom after urinating felt strange, leaned on a table, walked 20 feet and fell unconscious cutting her arm. While in the hospital she did not feel well on arising one morning and after leaving the bathroom she fell unconscious for about 10 minutes. She was very pale. The patient had fainted in the past. There was no postural hypotension. An EEG was normal.

Case 8. A woman, aged 63, stayed in bed all day because of a sore throat. At 11:00 p.m. she went to the bathroom and came to her senses lying in the hall, her feet still in the bathroom. She had been incontinent of bowel. The next evening she went to the kitchen at 11:00 p.m. and found herself lying on the floor groaning. In neither spell was there a warning. She did not know about sweating or pallor. There was no tongue-biting or tendency to refaint on getting up. Cardiac monitoring for 1 week was negative. An EEG was normal.

Case 9. A diabetic man, aged 71 , in one month fainted briefly five times on arising after sleeping. He was pale and sweated heavily. Examination showed no diabetic neuropathy. The blood pressure lying was $200 / 80 \mathrm{~mm}$. $\mathrm{Hg}$ and on standing up fell to $140 / 80 \mathrm{Hg}$ without faintness. Again, daytime examination failed to reveal symptomatic postural hypotension.

Case 10. A man, aged 57, with carcinoma in both adrenal glands lost consciousness on three occasions on first getting up in the morning. Once he fell breaking a front tooth and on another occasion injuring his head. There was no warning and the patient was unaware of what happened. During the day the blood pressure was $120 / 70 \mathrm{~mm} . \mathrm{Hg}$ without postural change. However, when the effect of posture was tested at 6:00 a.m. before the patient had arisen for the day, the blood pressure quickly fell to $70 \mathrm{~mm}$. Hg. systolic and the patient felt faint. Adrenal function showed a limited reserve and on steroid therapy fainting stopped. This case illustrates the presence of severe postural hypotension on first arising and its absence 3 hours later.

Case 11. A man, aged 67, got up at 3:00 a.m. to go to the bathroom and lost consciousness, coming to his senses on the floor of the bedroom. There had been no previous episodes. There was no postural hypotension.

Case 12. A woman, aged 79 , shortly after arising in the morning, while taking a hot shower, fell headlong out on to the floor bruising herself. There was no evidence of a seizure. One month before she had slithered to the floor feeling faint. There was no postural hypotension.

Case 13. A man, aged 49, had pain in the rectum due to a prostatic disorder. He went to the bathroom in the night to apply a warm compress to the sacral region when he became weak, nauseated, faint, broke into a sweat and fell to the floor unconscious for a few seconds. There was no postural hypotension.

Case 14. A woman, aged 62, with hypertension, on getting up ohe morning crossed the bedroom and fell unconscious striking her head on a dresser. There was no postural hypotension. There was no recurrence in 4 years.

Case 15. A woman, aged 82, got up to answer her doorbell and fell unconscious in the doorway. She became lucid almost immediately. There had been no previous episode. There was no convulsion. There was no postural hypotension. The carotid sinnues were not sensitive to pressure. There was no conduction abnormality in the ECG. 
Case 16. A woman, aged 63 , had 5 episodes of faintness in one month. In each she became sick, weak, pale and faint and had to lie down as vision became gray. Four spells occurred in the morning at breakfast. On other occasions fainting was prevented by lying down quickly. When first married she fainted on cutting her finger and fell fracturing a rib. She often fainted during her first pregnancy. Two years before she had fainted while standing in line. Her daughter fainted as a child when her hair was combed and continued to faint frequently through the years. Her son fainted at his own wedding and again while making a speech. Her mother and father never fainted. Postural hypotension usually could not be documented but on one occasion in hospital while she was sitting eating breakfast on first arising the systolic blood pressure was $60 \mathrm{~mm}$. $\mathrm{Hg}$. on standing.

Case 17. A man, aged 54, got up at $4: 45$ a.m. and fainted. He had always fainted easily, for example, just talking about an operation, at the sight of blood, watching an accident scene at the cinema and once when the dentist showed him his wife's extracted tooth.

Summary: Of the 17 patients 9 were male and 8 were female. Their ages ranged from 49 to 83 years. Eleven patients had only a single spell, 2 had two and 4 had several. The sporadic occurrence in most cases appears to be typical. Faintness occurred on arising before going to the bathroom in all cases except case 7. Four patients had fainted under other circumstances. On examination during the day no patient showed orthostatic hypotension but in three it was present when the patient was tested on first getting out of bed in the morning.

Comment: In fainting during the night or at dawn emphasis is usually placed on the role of micturition. For example, Gastaut (1956) described a special group of 40 subjects, 40 to 50 years of age, who fainted on awakening at night, going to or returning from the toilet or while still there. Thirty five of the 40 were males. Vasovagal syncope was favored by the upright position and the need to urinate in constitutional vagotonics in the phase of nocturnal hypervagotonia. Visceral distention and the parasympathetic discharge on empty- ing the bladder were essential factors. Dermksian and Lamb (1958) in their 82 cases of syncope in young adults included 11 in whom it was related to getting up from bed, 3 while urinating, 8 after alcohol ingestion, and 5 associated with gastroenteritis. Lukash et. al. (1964) concluded that orthostatic hypotension alone was not sufficient to produce micturition syncope but required the addition of cardioinhibitory reflexes from a full bladder associated with urgency. Salomon (1959) on the other hand claimed that from his clinical experience, failure of orthostasis was the principal cause.

In the present small group of cases the occurrence of nocturnal syncope before micturition or unrelated to it and in males and females in equal numbers suggests that micturition is an epiphenomenon in nocturnal syncope merely providing a sufficiently long period of motionless upright posture to precipitate severe postural hypotension. The above reports probably reflect the special selection for study of young male members of the military. A special predilection to orthostatic syncope after a period of sleep is probably of greater importance. Furthermore, micturition syncope does not occur during daytime activities.

Orthostatic hypotension as a specific nocturnal reaction is an accepted phenomenon but documentation is not common. MacLean et. al. (1944), using the Flack test, identified a group of subjects with "inconsistent orthostatic failure of the venous return" who in the erect posture showed a compensatory tachycardia and occasionally a fall in blood pressure and whose signs and symptoms were usually "much worse in the morning after the patient first gets out of bed and quickly improved." These subjects were more likely than normal men and women to faint occasionally, after prolonged rest in bed, during the first few months of pregnancy, under anxiety, with dehydration from heat, or after the use of alcohol and cathartics. The authors pointed out that in idiopathic postural hypotension symptoms were worse in the morning and this was prevented by having the patient sleep with the head of the bed elevated. Bannister et. al. (1967) noted the same morning tendency and attributed it in part to the fall of blood volume overnight which in normal persons is 150 to 200 $\mathrm{ml}$. In three of the present cases orthostatic hypotension was present in the early morning and not later in the day. Pickering (1965) found profound blood pressure falls during sleep and postulated that baroreceptors did not function during sleep or the number and pattern of impulses the receptors sent to the central nervous system were altered or the response to a given set of afferent impulses was altered. Since many of the patients are elderly, it is well to recall that Johnson et. al. (1965) found that 11 of 100 subjects over 70 years of age had at least a 20 $\mathrm{mm}$. $\mathrm{Hg}$ fall of systolic blood pressure on sitting up and 17 of 100 on standing up.

The evidence favors the conclusion that during sleep the baroreceptor apparatus is lulled into temporary hyporeactivity or depression that in certain predisposed individuals under certain predisposing circumstances (alcoholic ingestion, fatigue, etc.) results in symptomatic nocturnal or arousal postural hypotension. An investigation of this state using the technique of applying a negative pressure externally to the lower limbs would be of interest, particularly after a period of sleep. The Flack test could be further utilized for its diagnostic value.

Are there other examples of sleep resulting in a temporary maladaptation upon arousal? The frequent onset of vertigo upon the first movement after awakening in the morning may represent a similar reaction to rotational forces in the inner ear. Morning vomiting in pregnancy, petit mal lapses on first arising in the morning and the temporary mobility of Parkinsonian patients on first awakening may represent analogous reactions.

\section{B) Related to Alcohol Ingestion}

Alcohol is commonly included in the list of factors that predispose to syncope in susceptible persons but actual case descriptions are rarely included. MacLean et. al. (1944) mentioned this effect of alcohol. Lyle 
et. al. (1961) incriminated alcohol in 14 of 25 episodes of micturition syncope and Dermksian and Lamb (1958) in 8 or 82 cases of syncope in young adults. A patient of Donker et. al. (1972) with micturition syncope had drunk beer the evening before. The present six patients are examples of the role of alcohol in fainting in adults.

Case 1. A woman, aged 55, after one cocktail (30 ml whiskey) would become faint when standing. On one occasion after two cocktails while seated she became ashen and deeply unconscious. There was no recurrence in 6 years. There was probably a tendency to hypotension normally while standing.

Case 2. A man, aged 62 , on three occasions after a cocktail and just before eating, broke into a cold sweat, felt faint at the table and had to lie down. If he got up too soon he felt faint again. Occasionally on getting out of bed in the morning he experienced a cold sweat and weakness. There was no postural hypotension.

Case 3. A man, aged 66, at a banquet after having two cocktails and hors d'oeuvres sat down at the table, and said "I don't feel good" and regained consciousness on a stretcher being transported to the hospital. He was pale and spoke weakly but sweating was not described. An EEG and ECG monitoring were normal. There was no recurrence in 7 years.

Case 4. A man, aged 55, having drunk about $200 \mathrm{ml}$ of gin on a hot evening awakened two hours after retiring, sweating and nauseated. He rose to get fresh air, felt faint, called out and slumped to the floor striking his head thereby sustaining a subdural hematoma. An EEG was normal. There were no further spells in the next year. There was no postural hypotension.

Case 5. A woman, aged 66, in good health, while serving herself at a buffet luncheon fell to the floor unconscious without warning. She regained consciousness in about 30 seconds and was immediately lucid. Her pulse was not taken. She had drunk $15 \mathrm{ml}$ of whiskey in the previous 15 minutes. There was no history of faintness even with alcohol. Investigation showed no cardiac disease or postural hypotension. An EEG was normal. There was no recurrence in the next 2 years.

Comment: The mechanism by which alcohol causes postural hypotension has not bee investigated. The hypotensive effect certainly can precede intoxication and is facilitated when alcohol is taken on an empty stomach. Vasodilatation as a result of depression of central vasomotor reflexes could be a factor. The sporadic occurrence remains unexplained.

\section{C) Miscellaneous cases}

These six cases in which the mechanism appeared to be postural hypotension are included for the sake of completeness as examples of syncope occurring under an assortment of circumstances. The comment under $4 \mathrm{a}$ applies here.

Case 1. A man, aged 80 , while standing fell back unconscious, striking his head and regained consciousness almost immediately. Another time while seated he fell off his chair but recalled striking the floor. Once at dinner he felt faint and was placed on the floor without loss of consciousness. There was pallor and sweating and he was confused for 15 to 20 minutes. In another attack while standing he felt faint and started to sit down but fell fracturing some ribs. In addition, he had many brief spells of faintness lasting 5 to 10 seconds. Four vessel cranial angiography was normal. An EEG and ECG were normal. The patient had postural hypotension that was difficult to demonstrate but on one occasion the pressure fell to $85 / 60 \mathrm{~mm}$. Hg without symptoms.

Case 2. A man, aged 58, in about 35 years had six episodes of unconsciousness. One occurred after two alcoholic drinks and after lying down for 15 minutes he fainted again on trying to sit up. Two episodes occurred while standing urinating. The patient became very pale, sweated and lay still. Usually he regained consciousness in 5 minutes but on one occasion, according to his wife, it took 25 minutes. There were no presyncopal episodes. The blood pressure fell from 180 to $140 \mathrm{~mm}$. Hg. systolic on standing up. There was no convulsive activity and an EEG was normal. On phenytoin therapy the spells ceased but they did not recur when the medication was stopped. There was no undue sensitivity to carotid sinus pressure.

Case 3. A woman, aged 65 , fainted while doing her laundry. On another occasion she fainted after climbing a flight of stairs and again while in the hospital sitting in line awaiting an $x$-ray. She had other spells in which she felt faint and had to lie down. At times, however, her face was absolutely colorless yet she disclaimed any feeling of faintness. The blood pressure was $150 / 80$ $\mathrm{mm} . \mathrm{Hg}$ and there was no postural fall.

Case 4. A woman, aged 78 , had several episodes of complete or partial unconsciousness. While in the bathroom combing her hair she complained of bilateral posterior neck pain at the level of the 5th cervical vertebra, slumped to the floor unconscious, came to her senses in a few seconds and vomited once. She was very pale. There was no tendency to refaint on getting up. Two similar spells occurred a month later, again with posterior neck pain and vomiting. An ECG was normal. Cardiac monitoring showed no arrhythmia. There was no postural hypotension or undue sensitivity to carotid sinus pressure. The resting pulse was 60 beats per minute.

Case 5. A woman, aged 62, lost consciousness briefly while seated under a large dryer at the hairdresser's.

Case 6. A woman, aged 65, reported that if her bowels did not move for 3 days she might feel faint on getting out of bed. Twice under a hairdryer at a hair salon she felt hot, nauseated, weak and pale as if on the verge of fainting. Lying down relieved the feeling. A few times while standing at the sink doing the dishes she felt faint. She thought all abnormal spells were related to the state of her bowels. Laboratory studies were normal and there was no postural hypotension.

\section{CASES SUGGESTING AKINETIC SEIZURES}

Akinetic seizures may be defined as nonconvulsive transient brief episodes of unconsciousness of cerebral origin not attributable to ischemia. Under Group I it was remarked that the subject was not precisely delineated in the literature. In their authoritative account Gastaut et. al. (1974) fail to include within their definition not only cases in Group la but also the 10 cases in the present group.

Case 1. A man, aged 76, undergoing a progressive impairment of memory, in 2 or 3 years fell scores of time usually saying "here we go again" and lay on the floor as in a faint. Consciousness was lost briefly and recovery was good within a few minutes. There was some pallor but no sweating. Attacks came while lying, sitting or standing. He never fell heavily but let himself down. The pulse was strong throughout and no convulsive activity was observed. An EEG was normal. Anticonvulsant medication was ineffective. 
Case 2. A man, aged 82 , for 10 years had spells twice a week in which blood "surged" to his head and he was briefly out of touch. About twice a year he fell to the floor unconscious, limp, without a convulsion. An EEG was normal. Phenytoin was ineffective.

Case 3. A man, aged 67, who later proved to have a chronic subdural hematoma, was seated at church when he lost consciousness for a few minutes, following which he spoke clearly. There was no jerking or sweating. He had several more spells in which he felt himself sinking and lost consciousness briefly. Pallor occurred in all attacks. Following surgical removal of the subdural hematoma there were no further attacks in the next 6 years.

Case 4. A woman, aged 28, while pregnant, said to her husband as they sat eating, "I think I'm going to faint". She became pale, sweated and fell forward across the dishes in front of her, losing consciousness briefly. Her husband, a physician, found her pulse strong. She was well until 4 years later when she began to have minor spells in which the thread of consciousness was interrupted very briefly. They began with a haze before the eyes and ended in a few seconds without convulsive phenomena. Twice she fell and in another spell a motor accident occurred. An EEG was normal.

Case 5. A man, aged 67, gave a history of a cerebral embolism with good recovery. Four months later he began to have episodes of loss of consciousness in which he fell heavily. His daughter, a nurse, observed several spells and reported that he was always limp and never stiffened, jerked or bit his tongue. He regained consciousness in about 1 minute and was immediately lucid. Good control followed phenytoin therapy.

Case 6. A man, aged 71, without obvious cause ran off the road in his auto. Because of an abnormal EEG he was started on phenytoin therapy. Four years later while standing, talking to his family he abruptly lost consciousness for 5 minutes with pallor and slight sweating. The patient was limp without convulsive activity. He was confused for 5 minutes afterwards. The pulse was not taken. An ECG and CT scan were normal.

Case 7. A girl, aged 16, had three 15 second spells of unconsciousness between the ages of 11 and 16. Two occurred while standing and one while seated. In two spells that were witnessed she fell and lay motionless without convulsive activity, tongue biting or incontinence. In the spell, while seated the patient recovered immediately without being laid down. An EEG was borderline abnormal because of paroxysms of high voltage slowing during hyperventilation. On anticonvulsive therapy there were no further spells in 5 years.

Case 8. A woman, aged 68 , for $11 / 2$ years, every 2 months, had an episode consisting of a tickle in the throat, a slight cough and a little choking followed by loss of consciousness for 15 to 20 minutes. There was no convulsion, incontinence or tongue biting.

Case 9. A woman, aged 47 , in 20 years had approximately 50 sudden attacks lasting up to 30 minutes and on one occasion 2 hours in which she lost consciousness, was very pale and appeared dead. The spells began with a sensation in the abdomen which rose to her head as she lost contact. At least 15 spells were witnessed and no convulsion was observed. An ECG and a sleep EEG were normal. On phenytoin therapy there were only two minor spells in the next 4 years.

Case 10. A man, aged 92, had recorded 59 spells in the previous $31 / 4$ years in which he felt faint and quickly lay down. The spells lasted $1 / 2$ to 5 minutes and there was no dizziness. Afterwards he sweated. The pulse was maintained. Some occurred as he dropped off to sleep. When asked if he was dizzy he said "more twizzy" and referred to the spells as "the twizzies". Four years later at the age of 96 he reported that on phenobarbital therapy he had had no more spells.

Two additional cases are appended because special observations showed that the original interpretation of akinetic seizures was wrong.

Case 11. A man, aged 61, fell unconscious four times in one year, each spell beginning with an increasingly warm feeling in the epigastrium. All attacks were witnessed and the patient was seen to collapse sudderily, lie quietly for 15 seconds and then abruptly regain consciousness and lucidity. The eyes were closed and he was very pale and sweaty. There was no convulsive activity. The pulse was not taken. An EEG and ECG monitoring were normal. In a fifth spell in which the patient was unconscious for 4 minutes, a companion supported the patient and through the clothing could feel a slight but definite rhythmic jerking of the trunk for about 1 minute followed by limpness and unconsciousness for $3 \mathrm{~min}$ utes. This is an example of minor spells failing to show jerking which was present in a stronger spell. The attacks ceased with phenytoin therapy.

Case 12. A man, aged 54, while standing speaking to a relative, felt "unreal" as if another thought were crowding out what he was discussing. He excused himself, walked 7 meters to look out the window and fell with a crash lying full length and motionless without jerking or spasm. In 20 seconds he opened his eyes, said "What happened?" and started to get up. He was slow in his reactions but walked without help. He remained ashen for about 7 minutes. There was no incontinence. A sleep EEG and a CT scan were normal. One year later he had another attack carefully observed by his wife. After saying he thought he was having "another one" he shook all over, head, arms, and legs, for no more than 4 seconds after which his body stiffened and his neck retracted for no more than 2 seconds. In another 2 seconds he said "What happened?" This is, therefore, not a case of akinetic seizure but rather illustrates that within no short a time as 5 or 6 seconds of the patient being heard to fall, all signs of a convulsion may have subsided.

Summary: The ages ranged from 16 to 92 years. The pulse was present during an episode in Cases 1 and 4 . In eight cases there were numerous spells over many months unlike the history in Stokes-Adams attacks. Furthermore, the patients aged 28 and 16 were not candidates for cardiac disease. Anticonvulsants were used in 9 cases and may have been effective in 7. An EEG available in 7 cases was normal in 5 , abnormal in 2. A focal disease process was present in only two cases (3 and 5).

Comment: These cases are presented as support for the proposal that akinetic seizures are an entity which occur in the absence of any other type of seizure and in most cases without signs of focal brain disease. Obviously in the interpretation of non-convulsive syncopal episodes it is most important to have further information on the existence of this type of attack. Unfortunately, the present cases offer only circumstantial evidence although some are rather persuasive (cases 1 to 5). It is assumed, of course, that eyewitness accounts have been accurate.

The Type 2 akinetic seizures of Gastaut et. al. (1974), that is classical 
focal seizures which at times are limited to akinetic attacks comprise a bonafide category, although descriptions of actual cases are almost nonexistent. The present author has been able to document the occurrence of akinetic attacks in 20 cases of epilepsy, mainly frontal and temporal foci, leaving no doubt that such akinetic seizures do occur. The problem thus resolves itself into the question of whether akinetic seizures of the type under discussion here really exist. On the assumption that the answer will be in the affirmative, they could be tentatively designated "Type 3". An EEG recording during an attack is an unlikely prospect and the use of Metrazol or other special activating techniques would be informative, but might be hard to justify.

\section{MISCELLANEOUS}

This group contains three cases that are unusual and two that illustrate stumbling blocks in diagnosis.

Case 1. A man, aged 65, with atlantooccipital fusion and signs of posterior fossa compression, in 7 years had about 25 episodes in which while seated or standing he became pale, felt light-headed and did not respond for a few seconds. He recovered slowly passing through a stage of confusion and in a few hours was back to normal. There was no accompanying headache and no relation to head movements. Although this may be an example of the "sinking spell" of hydrocephalus, Dobkin (1978) presented evidence for transient brain stem dysfunction as a result of compression and shearing forces secondary to a brief rise in intracranial pressure.

Case 2. A man, aged 43 , stated that 8 months before he had twice lost consciousness while laughing excessively. Occasionally he became dizzy on laughing. The spells were not cataplectic and no cause was elicited.

Case 3. A woman, aged 49 , twice a year for 20 years had unusual spells which she described as explosions inside her head.
First she noted wavering of vision and faintness, followed by a loud "phoom" sound in her head associated with nausea. She was obliged to vomit and became cold and sopping wet. She stayed fixed in one position for up to an hour and a half. There was no pallor and she never lost consciousness completely. She thought that by concentrating she could abort the spell. One EEG was normal, another diffusely abnormal. This spell is difficult to categorize.

Case 4. A man, aged 87 , had several episodes in which he fell unconscious to the floor and was poorly responsive for up to an hour. He proved to be a secret Demerol addict, using several hundred mg. daily by injection. The spells ceased after discontinuing the drug.

Case 5. A woman, aged 43, complained of 7 brief episodes of loss of consciousness in one month. Although she felt weak she did not fall. She disclaimed vertigo but on having her quickly change position from lying to sitting, she closed her eyes, felt giddy and returned to normal in about 10 seconds. This was a replica of her spontaneous attacks and after it had been reproduced several times a diagnosis of labyrinthine vertigo associated with alarm was made. This situation, which is not rare, might be termed the false syncope of vertigo.

\section{CONCLUDING REMARKS}

The main purpose of this paper has been the presentation of a large sample of cases of syncope or loss of consciousness that do not fall conviently into recognized categories. Since the cases are heterogeneous and bear upon numerous different aspects of the overall problem of syncope, a brief discussion has been included with each of the more important groups of cases and further general discussion here is unnecessary.

\section{REFERENCES}

BANNISTER, R., ARDILL, L., and FENTEM, P. (1967) Defective autonomic control of blood vessels in idiopathic orthostatic hypotension. Brain 90, 725-746.
DHINGRA, R. C., DENES, P., WU, D., CHUQUIMIA, R., AMAT-Y-LEON, F., WYNDHAM, C. and ROSEN, K. M. (1974) Syncope in patients with chronic bifascicular block. Ann. Int. Med. 81, 302-306.

BONDUELlE, M., and SAlLOU, C. (1956) Signes cliniques et E.E.G. de l'épilepsie digestive. Rev. Neurol. 95, 540-541.

DERMKSIAN, G., and LAMB, L. E. (1958) Syncope in a population of healthy young adults. J.A.M.A. 168, 1200-1207.

DOBKIN, B. H. (1978) Syncope in the adult Chiari anomaly. Neurology $28,718-720$.

DONKER, D. N. J., ROBLES DE MEDINA, E. O., and KIEFT, J. (1972) Micturition syncope. Electroencephalog. Clin. Neurophysiol. 33, 328-331.

FISHER, C. M. (1967) A particular kind of syncope. Trans. Am. Neurol. Assoc. 92, 230231.

GASTAUT, H. (1956) La syncope nocturne des hypervagotoniques, sa différenciation d'avec l'épilepsie morphéique. Rev. Neurol. (Paris) $95,420-421$.

GASTAUT, H., BROUGHTON, R., ROGER, J., and TASSINARI, C. A. (1974) In, Handbook of Clinical Neurology (Vinken, P. J., and Bruyn, G. W.) North Holland Publishing Company, Amsterdam. Vol. 15, pp. 130-144.

JOHNSON, R. H., SMITH, A. C., SPALDING J. M. K., and WOOLNER, L. (1965) Effect of posture on blood-pressure in elderly patients. Lancet 1, 731-733.

LUKASH, W. M., SAWYER, G. T., and DAVIS, J. E. (1964) Micturition syncope produced by orthostasis and bladder distension. New. Eng. J. Med. 270, 341-344.

LYLE, C. B., MONROE, J. T., FLINN, D. E., and LAMB, L. E. (1961) Micturition syncope: Report of 24 cases. New Engl. J. Med. 265, 982-986.

MacLEAN, A. R., ALLEN, E. V., and MAGATH, T. B. (1944) Orthostatic tachycardia and orthostatic hypotension: Defects in the return of venous blood to the heart. Am. Heart J. 27, 145-163.

PICKERING、G. (1965) Hyperpiesis: High blood pressure without evident cause: Essential hypertension. Brit M. J. 2, 959-968.

SALOMON, M. I. (1959) Letter to Editor, New Engl. J. Med. 260, 942.

SCHEIMAN, M., WEISS, A., and KUNKEL, F. (1973) His bundle recordings in patients with bundle branch block and transient neurological symptoms. Circulation 48, 322330.

SIMPSON, K. (1949) Deaths from vagal inhibition. Lancet I, 558-560. 